\title{
Uncertainty in watershed response predictions induced by spatial variability of precipitation
}

\author{
Chia-Ling Chang • Shang-Lien Lo • \\ Ming-Ying Chen
}

Received: 6 January 2006 / Accepted: 18 April 2006 / Published online: 14 December 2006

(C) Springer Science + Business Media B.V. 2006

\begin{abstract}
Negligence to consider the spatial variability of rainfall could result in serious errors in model outputs. The objective of this study was to examine the uncertainty of both runoff and pollutant transport predictions due to the input errors of rainfall. This study used synthetic data to represent the "true" rainfall pattern, instead of interpolated precipitation. It was conducted on a synthetic case area having a total area of 20 $\mathrm{km}^{2}$ with ten subbasins. Each subbasin has one rainfall gauge with synthetic precipitation records. Six rainfall storms with varied spatial distribution were generated. The average rainfall was obtained from all of the ten gauges by the arithmetic average method. The input errors of rainfall were induced by the difference between the actual rainfall pattern and estimated average rainfall. The results show that spatial variability of rainfall can cause uncertainty in modeling outputs of hydrologic, which would be transport to pollutant export predictions, when uniformity of rainfall is assumed. Since rainfall is essential information for predicting watershed responses, it is important to consider the properties of rainfall, particularly spatial rainfall
\end{abstract}

\section{C.-L. Chang $(\bowtie)$}

Department of Environmental resources management, Chia Nan University of Pharmacy \& Science, No. 60, Erh-Jen Rd., Sec. 1, Jen-Te, Tainan, Chinese Taiwan e-mail: f89541201@ntu.edu.tw

\section{S.-L. Lo · M.-Y. Chen}

Graduate Institute of Environmental Engineering,

National Taiwan University, Taipei 106, Chinese Taiwan variability, in the application of hydrologic and water quality models.

Keywords Precipitation $\cdot$ Rainfall $\cdot$ Spatial variability · Uncertainty · Watershed response

\section{Introduction}

Efficient water resource and watershed management is required to protect downstream people from flooding, debris flows and pollutant impact. The strategies and programs of watershed management always depend on the modeling results of watershed responses, involving flow and pollutant transport process. Abundant hydrologic and water quality models have been developed and applied in many studies. In applying hydrology and water quality models, rainfall is critical information, because it activates watershed response in hydrologic systems (Chaubey et al., 1999). Even though the important of spatial rainfall variability was recognized more than three decades ago (Osborn and Reynolds, 1963; Rodda, 1967; Dawdy and Bergman, 1969), rainfall is still generally taken as spatially uniform, due to the limitation of measured precipitation (Goodrich et al., 1995). Negligence to consider the spatial variability of rainfall could result in serious errors in model outputs. A rainfall storm observed by a single gauge or a few gauges can bring a noticeable input error, particularly when a dense network of rainfall gauges are necessary to adequately describe rainfall over a watershed. 
Most of the past studies have primarily focused on the assessment of the influence of spatial rainfall variability on hydrologic responses, such as runoff volume, time to peak runoff, and peak runoff rate. Information on the effect of spatial rainfall variability on pollutant transport is limited. The objective of this work was to examine the uncertainty of both runoff and pollutant transport predictions due to the input errors of rainfall. The spatial rainfall variability could result in the uncertainty in runoff predictions. The uncertainty in modeling results of hydrological responses would transport to pollutant export predictions. This study used synthetic data to generate actual rainfall pattern. The input errors of rainfall were induced by the difference between the actual rainfall pattern and estimated average rainfall by the arithmetic average method. WinVAST model was applied to predict watershed responses. Understanding of the relationship between input uncertainty caused by spatial rainfall variation and predicted watershed responses would improve the efficiency of watershed management.

\section{Methods}

Since rainfall gauges are impossible to be set everywhere within a watershed, spatial variability of rainfall can be expected to increase with an increase in the watershed size. In most of the past works, methods of precipitation interpolation, such as Thiessen Polygons method and Kriging method, were applies to capture the "true" rainfall pattern. This study used synthetic data to represent the "true" rainfall pattern, instead of interpolated precipitation. Even though some work mentioned that the synthetic storm might not adequately model the patterns and amount of actual rainfall, most studies still expounded that synthetic data is useful for overcoming the restriction of monitored information (Hromadka, 1996a,b). This study was conducted on a synthetic case area, shown in Fig. 1, having a total area of $20 \mathrm{~km}^{2}$ with ten subbasins. The subbasin area, stream length, average slope, landuse condition of each subbasin were assumed to be all the same. The area of each subbasin was $2 \mathrm{~km}^{2}$. The length of the main stream in each subbasin was $2000 \mathrm{~m}$. The average slope in the case area was 5\%. The land-use condition in the watershed was forest, and the curve number (CN) was 70. The pollutant loading of suspended solids (SS) for forest was $0.15 \mathrm{~kg} / \mathrm{ha} / \mathrm{day}$. The peaking factor for

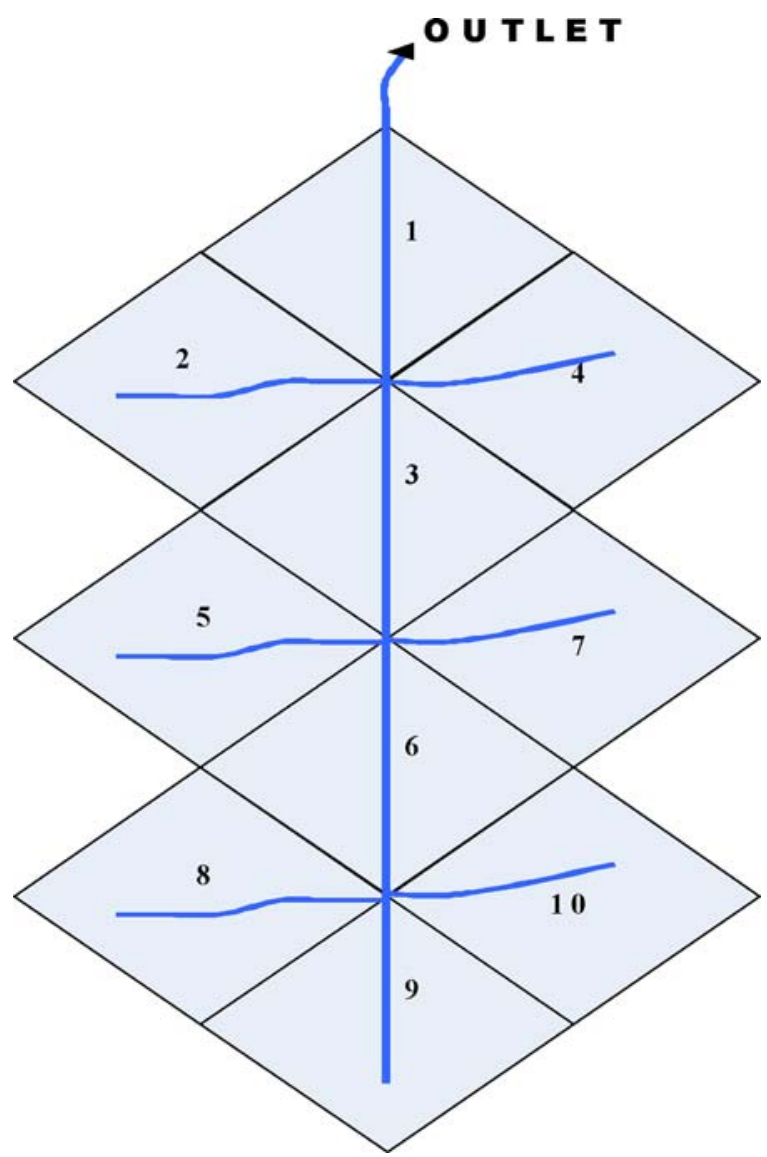

Fig. 1 Synthetic case area with ten subbasins.

SCS unit hydrograph was 484 . The Muskingum parameters, involving weight factor, $\mathrm{X}$, and routing constant, $\mathrm{K}$, were $2 \mathrm{hrs}$ and 0.2 separately.

Each subbasin has one rainfall gauge with synthetic precipitation records. The average precipitation depth in each subbasin was $30 \mathrm{~mm}$, and the rainfall duration was $5 \mathrm{hrs}$ for each synthetic rainfall event. Six rainfall storms with varied spatial distribution were generated, shown in Table 1. The standard deviation of precipitation in each subbasin, which represents the degree of spatial variability of rainfall, was $0,18.7,25.4,36.0$, 45.8 and $53.9 \mathrm{~mm}$ separately. The average rainfall was obtained from all of the ten gauges by the arithmetic average method. The input errors of precipitation were induced by the difference between the actual rainfall pattern and estimated average rainfall.

This study applied WinVAST model to predict watershed responses. WinVAST model developed by the University of Virginia in 2003 is based on the windows interface, shown in Fig. 2. Its former version is 
Table 1 Six actual rainfall patterns with spatial variability

\begin{tabular}{|c|c|c|c|c|c|c|}
\hline subbain pattern & pattern 1 & pattern 2 & pattern 3 & pattern 4 & pattern 5 & pattern 6 \\
\hline subbasin 1 & 30 & 9 & 30 & 120 & 3 & 30 \\
\hline subbasin 2 & 30 & 24 & 33 & 30 & 15 & 180 \\
\hline subbasin 3 & 30 & 60 & 45 & 30 & 60 & 15 \\
\hline subbasin 4 & 30 & 15 & 75 & 60 & 9 & 30 \\
\hline subbasin 5 & 30 & 33 & 9 & 18 & 150 & 9 \\
\hline subbasin 6 & 30 & 3 & 12 & 12 & 3 & 24 \\
\hline subbasin 7 & 30 & 27 & 24 & 18 & 6 & 3 \\
\hline subbasin 8 & 30 & 45 & 3 & 6 & 9 & 3 \\
\hline subbasin 9 & 30 & 30 & 3 & 3 & 36 & 3 \\
\hline subbasin 10 & 30 & 54 & 66 & 3 & 9 & 3 \\
\hline ave_precipitation & 30 & 30 & 30 & 30 & 30 & 30 \\
\hline std_precipitation & 0 & 18.7 & 25.4 & 36.0 & 45.8 & 53.9 \\
\hline
\end{tabular}

Note: ave_precipitation: the average of precipitation in each subbasin std_precipitation: the standard deviation of precipitation in each subbasin. All data on precipitation patterns is in $\mathrm{mm}$.

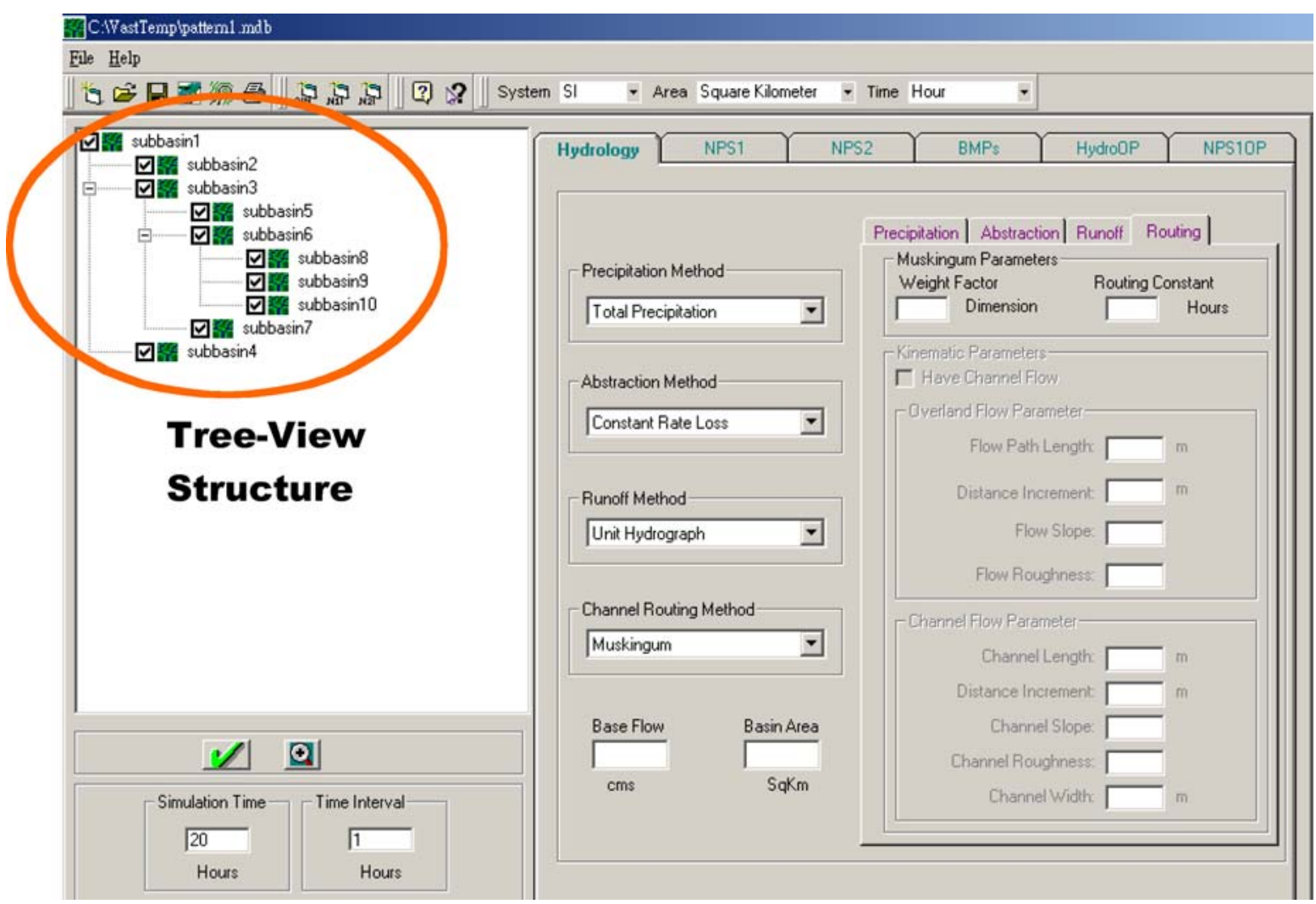

Fig. 2 Windows interface of WinVAST model.

VAST model. WinVAST is an event-oriented model. It combines widely-used techniques, which involve calculating rainfall abstractions, generating overland flow hygrographs, estimating flood routing from upstream subbasins to downstream subbasins, computing non-point source pollution (NPSP) wash-off from subbasins, simulating routing pollutants, and predicting the condition through selected best management practices (BMPs). WinVAST model treats multi-catchment basins as a tree-view structure, so a complex 

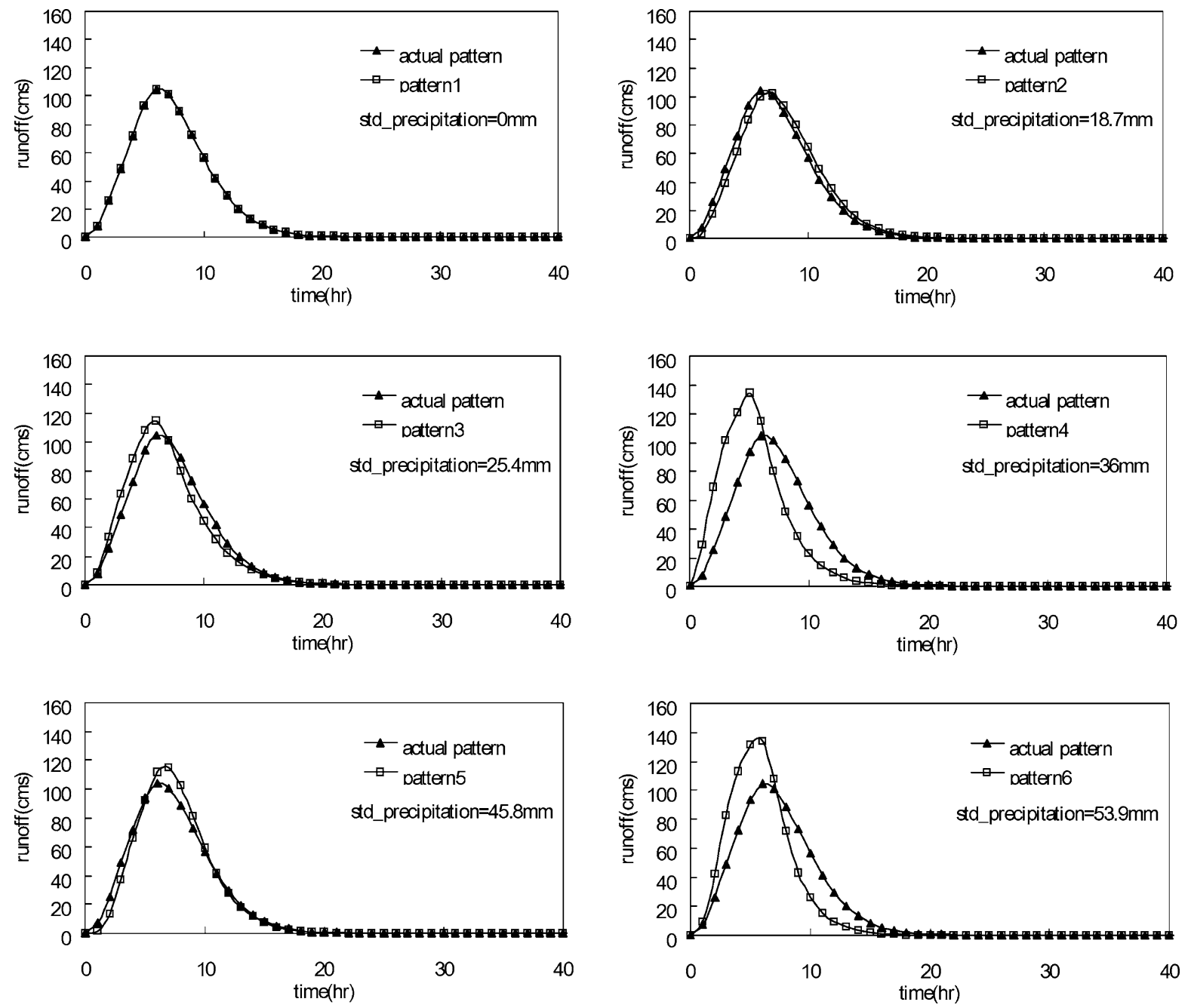

Fig. 3 Hydrographs under actual and estimated rainfall patterns.

representation of the entire catchment basin can be easily generated (Tisdale et al., 1996; Yu et al., 2003).

\section{Results and discussion}

The results demonstrate that spatial rainfall variability can exactly influence watershed responses. The input errors of precipitation can result in the uncertainty on modeling outputs of flow hydrographs, representing flow volume, peak flow, arrival time of peak flow, and so on. The uncertainty on hydrologic responses would transport to pollutant exports, and even be expanded. Figure 3 shows the hydrographs under actual and estimated precipitation patterns. When the standard deviation of precipitation in each subbasin increases, the spatial variability of rainfall would be more noticeable. If we ignore spatial rainfall variation when the variability is serious, the estimated error of hydrologic responses might be larger. However, the results show that it is not an inevitable trend. The correlation coefficient between the degree of spatial precipitation variability and the estimated error of peak flow, as rainfall taken spatially uniform, is around 0.77 . However, the correlation coefficient between the grade of spatial rainfall variation and the estimated error of SS concentration and loading is just about 0.56 and 0.23 separately.

Figures 4 and 5 shows the SS exports under actual and estimated precipitation patterns. The degree of 

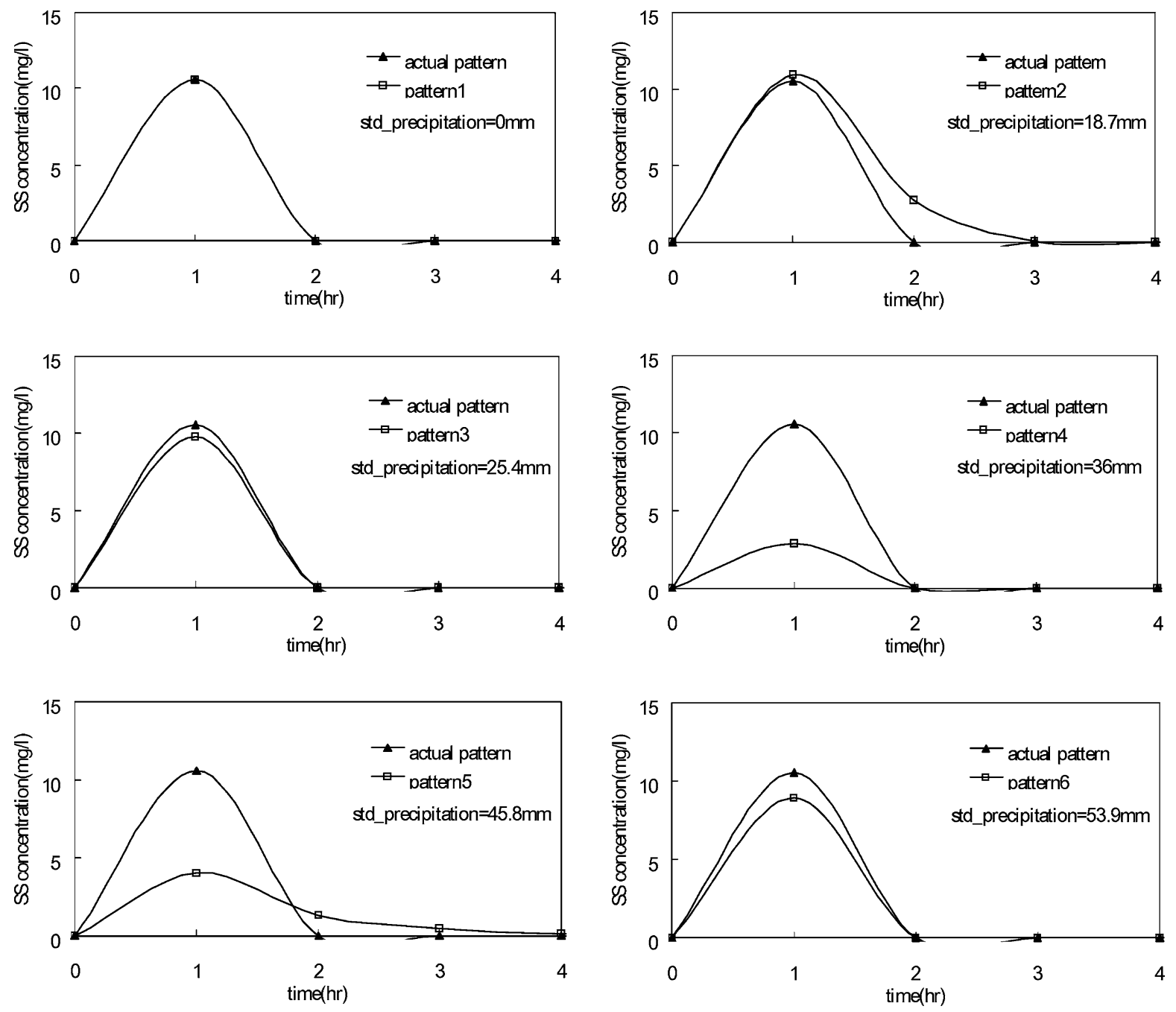

Fig. 4 SS concentration under actual and estimated rainfall patterns.

estimated error in runoff prediction is not highly relative to it in pollutant exports simulation. The correlation coefficient between estimated error of peak flow and estimated error of SS concentration and SS loading is about 0.44 and -0.33 separately. In addition, the correlation coefficient between estimated error of SS concentration and SS loading is around 0.51. Although correlation analysis could be more correct based on a large number of data, the results herein can still display the sketchy trend between the degree of spatial rainfall variability and estimated error of watershed response predictions, and the degree of estimated errors of hydrologic responses and pollutant exports. Moreover, the correlation coefficient assessed in this work shows the uncertainty of modeling exports could be transported and increased in watershed simulation.

The uncertainty in modeling is usually induced by unknown errors. The spatial variability of rainfall in a watershed is not easy to be understood, by reason for the limited number of monitored rainfall gauges. Therefore, the uncertainty in modeling outputs would be complex and even enlarged in each step of simulation. However, the modeling results and watershed responses predictions are significant for developing watershed management strategies. Thus, it is crucial to lessen the uncertainty of model input. As shown in the results of the synthetic case study, it did demonstrate the importance of spatial variability of rainfall. In 

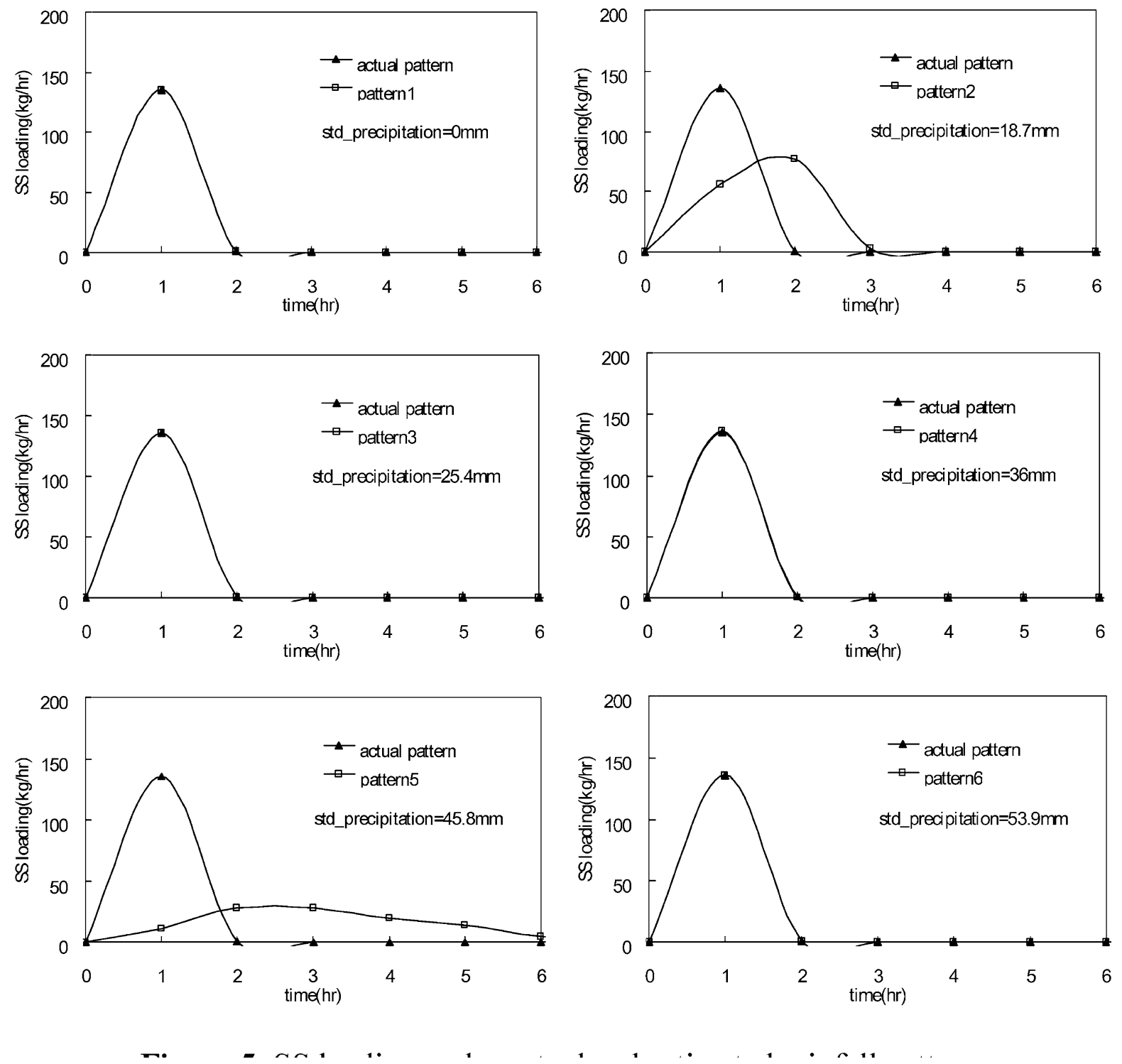

Fig. 5 SS loading under actual and estimated rainfall patterns.

watershed modeling, clearly understanding of rainfall characteristics would help us lower the uncertainty in the prediction of watershed responses.

\section{Conclusions}

In modeling hydrologic and pollutant responses in a watershed, it may not be valid to assume the spatial homogeneity of rainfall. Most of time, spatial variability of rainfall can result in uncertainty in modeling outputs of hydrologic and water quality models when uniformity of rainfall is assumed. Since rainfall is essential information for predicting watershed response, it is important to consider the properties of rainfall, particularly spatial variability of rainfall, in the application of hydrologic and water quality models.

Acknowledgements The authors would like to thank the National Science Council of the Republic of China for financially supporting this research under Contract No. NSC 93-2211-E002-011. 


\section{References}

Chaubey, I., Haan, C.T., Salisbury, J.M., \& Grunwald, S. (1999). Quantifying model output uncertainty due to spatial variability of rainfall. Journal of American Water Resource Association, 35(5), 1113-1123.

Dawdy, D.R., \& Bergman, J.M. (1969). Effect of rainfall variability on strearnflow simulation. Water Resource Research, 5, 958-966.

Goodrich, D.C., Faures, J., Woolhiser, D.A., Lane, L.J., \& Sorooshian, S. (1995). Measurement and analysis of smallscale convective storm rainfall variability. Journal of Hydrology, 173, 283-308.

Hromadka, T.V. (1996). A rainfall-runoff probabilistic simulation program: 1. Synthetic data generation. Environmental Systems, 11(4), 235-242.
Hromadka, T.V. (1996). A rainfall-runoff probabilistic simulation program: 2. Synthetic data analysis. Environmental Systems, 11(4), 243-249.

Osborn, H.B., \& Reynolds, W.N. (1963). Convective Storm Patterns in the Southwestern United States. Bull IASH, 8(3), 81-83.

Rodda, J.C. (1967). The Systematic Errors in Rainfall Measurement. Journal of the Institution of Water Engeneering, London, 21, 173-177.

Tisdale, T.S., Kaighn, R.J., \& Yu, S.L. (1996). The Virginia storm (VAST) model for stormwater management - User's Guide version 6.0. Virginia, USA: University of Virginia, Charlottesville.

Yu, S.L., Stanford, R.L., \& Zhai, Y.Y. (2003). Virginia stormwater model for windows - User's Manual version 1.0. Virginia, USA: University of Virginia, Charlottesville. 